\title{
PENERAPAN MODEL WATERFALL PADA SISTEM INFORMASI PENGELOLAAN IURAN RUKUN KEMATIAN YAYASAN AL-HAMIDIYAH BERBASIS WEB
}

\author{
Lis Saumi Ramdhani ${ }^{1}$, Erika Mutiara² \\ 1,2 Universitas Bina Sarana Infromatika \\ e-mail: ${ }^{1}$ lis.lud@bsi.ac.id, ${ }^{2}$ erika.emb@bsi.ac.id
}

\begin{abstract}
Abstraksi
Yayasan Al-Hamidiyah merupakan sebuah yayasan yang berlokasi di Cisaat Kabupaten Sukabumi yang memberlakukan iuran rukun kematian bagi warga sekitar. Iuran tersebut merupakan iuran wajib bulanan yang dibayarkan warga (per-Kepala Keluarga) atas dasar kesepakatan bersama. luran ini bertujuan untuk meringankan beban anggota keluarga yang terkena musibah beban kematian. Dalam pengelolaan iuran kematian, seringkali terjadi iuran yang tidak merata dan pencatatan data yang tidak tertata sehingga mengakibatkan sulitnya mencari data yang sudah diinput sebelumnya. Adapun metode yang digunakan pada penelitian ini adalah metode kualitatif. Untuk mengatasi permasalahan tersebut, maka dibuatlah sistem berbasis web sebagai alat bantu dalam pengolahan data dan untuk menunjang pertanggungjawaban dalam penyajian laporan yang efektif dan efisien serta mempermudah dalam menghasilkan informasi yang berkualitas seperti yang dibutuhkan. Pembuatan sistem tersebut dikembangkan menggunakan model pengembangan perangkat lunak waterfall, dimulai dari analisa kebutuhan perangkat lunak, desain, pengkodean menggunakan bahasa php dan mysql, pengujian sistem dengan blackbox testing dan terakhir dilakukan maintenance. Dengan adanya sistem ini, proses pengelolaan iuran kematian antara pihak yayasan dan rukun kematian menjadi lebih terorganisir dengan baik dan dapat meningkatkan kualitas pelayanan serta efektivitas kinerja pihak yayasan.
\end{abstract}

Kata Kunci : Pengelolaan Iuran, Rukun Kematian, Sistem Informasi, Web

\begin{abstract}
Al-Hamidiyah Foundation is a foundation located in Cisaat, Sukabumi Regency, which imposes a death benefit contribution for local residents. The fee is a compulsory monthly fee paid by residents (per Head of Family) based on mutual agreement. This contribution aims to ease the burden on family members affected by the death burden. In the management of death contributions, there are often uneven contributions and recording of unorganized data, making it difficult to find data that has been previously inputted. The method used in this study is a qualitative method. To overcome these problems, a web-based system was created as a tool in data processing and to support accountability in the presentation of reports that are effective and efficient and make it easier to produce quality information as needed. The making of the system was developed using the waterfall software development model, starting from the analysis of software requirements, design, coding using php and mysql languages, testing the system with blackbox testing and finally maintenance. With this system, the process of managing death contributions between the foundation and the pillars of death has become more organized and can improve the quality of services and the effectiveness of the foundation's performance.
\end{abstract}

Keywords: Contribution Management, Pillars of Death, Information Systems, Web

\section{Pendahuluan}

Rukun kematian adalah suatu organisasi atau wadah kegiatan sosial yang memberikan pelayanan pada warga perumahan yang menjadi anggotanya, dimana pelayanan yang diberikan kepada para anggotanya berupa pelayanan jasa kematian seperti, perawatan jenazah (memandikan, mengafankan, serta melakukan sholat jenazah), sampai pada pengantaran jenazah ke pemakaman dan pengurusan pemakamannya (Jirhanuddin, Dakhoir, \& Sulistyaningsih, 2016). 
Di dalam rukun kematian tersebut terdapat iuran yang merupakan iuran wajib bulanan yang dibayarkan warga (per-Kepala Keluarga) atas dasar kesepakatan bersama (Muslimah, 2018).Tujuannya agar warga dapat bergotong royong dalam mengumpulkan sumbangan terhadap keluarga yang mendapat kemalangan untuk membantu meringankan beban keluarga yang terkena musibah (Hutari, 2018).

Yayasan Al-Hamidiyah merupakan sebuah yayasan yang berlokasi di Kelurahan Nagrak Kecamatan Cisaat Kabupaten Sukabumi yang mengelola iuran kematian bagi warga di RW 001 dan 010. Dalam pengelolaan iuran masih menggunakan proses pencatatan dalam bentuk kertas, sehingga sering terjadi kekeliruan dalam mencatat ataupun dalam merekap data iuran tiap bulan ataupun tiap tahun sehingga menghasilkan laporan yang kurang akurat (Widodo \& Herlawati, 2011) Selain itu kurangnya penataan berkas pada data iuran kematian menyebabkan sulitnya pencarian data-data sebelumnya karena dilakukan secara manual (Sari \& Nuari, 2017).

Maka dari itu dibutuhkanlah alat bantu berupa sistem informasi yang lebih terintegrasi dengan menerapkan model waterfall sehingga sistem informasi dapat menghasilkan informasi yang lebih cepat, tepat dan akurat.

\section{Metode Penelitian}

Metode yang digunakan dalam penelitian ini yaitu metode kualitatif. Metode kualitatif merupakan metode yang menggunakan data berupa narasi, deskripsi, dokumen tertulis maupun tidak tertulis(Gumilang, 2016). Dan untuk pengumpulan data dalam metode kualitatif melibatkan penggunaan dan pengumpulan berbagai bahan empiris, seperti studi kasus, pengalaman pribadi, instropeksi, riwayat hidup, wawancara dan pengamatan. Pada penelitian ini pengumpulan data yang diambil yaitu studi kasus pada yayasan Al-Hamidiyah dengan melakukan wawancara dan pengamatan langsung ke yayasan Al-Hamidiyah untuk mengetahui permasalahan yang dihadapi di tempat tersebut.

Untuk pengembangan perangkat lunak yang akan dibangun menggunakan model waterfall. Model waterfall merupakan model pengembangan sistem informasi yang sistematik dan sekuensial (Pressman,
2002). Model waterfall memiliki beberapa tahapan, yaitu:

a. Analisis kebutuhan perangkat lunak Proses pengumpulan kebutuhan dilakukan secara intensif untuk mespesifikasikan kebutuhan perangkat lunak agar dapat dipahami perangkat lunak seperti apa yang dibutuhkan oleh user. Pada tahap ini dilakukan analisis terhadap sistem iuran rukun kematian yang sedang berjalan di Yayasan AlHamidiyah, dengan mengumpulkan data-data iuran seperti data warga, data pembayaran, dan laporan yang berkaitan dengan iuran rukun kematian.

b. Desain

Tahap ini mentranslasi kebutuhan perangkat lunak dari tahap analisis kebutuhan ke representasi desain agar dapat diimplementasikan menjadi program pada tahap selanjutnya. Desain perangkat lunak yang dihasilkan pada tahap ini juga perlu didokumentasikan. Pada tahap desain dilakukan desain sistem dengan menggunakan UML dan desain basis data dengan menggunakan ERD dan LRS.

C. Pembuatan kode program

Desain harus ditranslasikan kedalam program perangkat lunak. Hasil dari tahap ini adalah program komputer sesuai dengan desain yang telah dibuat pada tahap desain. Untuk Pembuatan kode program menggunakan bahasa pemrograman php dan databasenya menggunakan MySql.

d. Pengujian

Pengujian fokus pada perangkat lunak secara dari segi lojik dan fungsional dan memastikan bahwa semua bagian sudah diuji. Hal ini dilakukan untuk meminimalisir kesalahan (eror) dan memastikan keluaran yang dihasilkan sesuai dengan yang diinginkan. Pada pengujian sistem informasi iuran rukun kematian menggunakan blackbox testing.

e. Pendukung (support) atau pemeliharaan (maintenance)

Tahap pendukung atau pemeliharaan dapat mengulangi proses pengembangan mulai dari analisis spesifikasi untuk perubahan perangkat lunak yang sudah ada tapi tidak untuk membuat perangkat baru. 


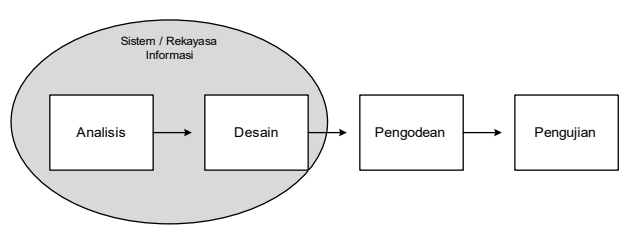

Gambar 1. Model Waterfall

Sumber: (Rosa \& Shalahuddin, 2015)

3. Hasil dan Pembahasan

3.1. Analisa kebutuhan perangkat lunak

A. Identifikasi masalah

Permasalahan yang diterjadi pada sistem pengelolaan iuran kematian di Yayasan AlHamidiyah adalah:

1. Pencatatan data iuran kematian menggunakan catatan dengan tulis tangan dan penyimpanan berkas data yang terdahulu tidak tertata dengan baik.

2. Penyajian laporan iuran kematian masih dilakukan dengan cara rekap ulaang dari data iuran tiap bulan.

B. Analisa Sistem

1. Data yang dicatat manual menyebabkan sulitnya melakukan pencarian data/berkas yang sudah diinput sebelumnya dan kemungkinan arsip atau dokumen yang disimpan rentan dari resiko kehilangan atau rusak.

2. keterlambatan informasi dalam pembuatan laporan sehingga untuk penyajian data memerlukan waktu yang lama (tidak efisien).

C. Kebutuhan Data

Data yang dibutuhkan dalam desain sistem informasi iuran rukun kematian ini diantaranya: data anggota, Data perlengkapan, Data petugas, data Pembayaran iuran bulanan, dan data pengeluaran.

D. Kebutuhan Fungsional

1. Proses login admin

2. Pengelolaan data oleh admin: data anggota, Data perlengkapan, Data petugas, data Pembayaran iuran bulanan, data pengeluaran, data jurnal dan data laporan.

\subsection{Desain}

Desain Sistem

a. Usecase Diagram

Usecase diagram adalah Diagram yang memperlihatkan himpunan use-case dan aktor-aktor. Diagram ini sangat penting untuk mengorganisasi dan memodelkan perilaku suatu sistem yang dibutuhkan diharapkan pengguna(Widodo \& Herlawati, 2011).

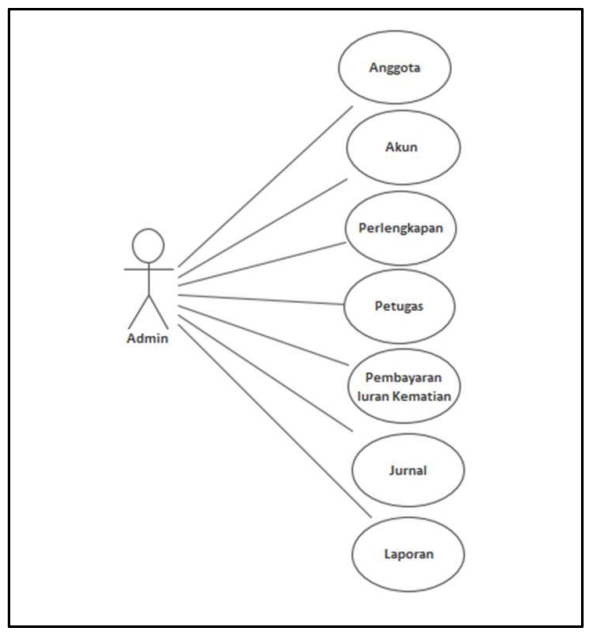

Gambar 2. Use Case Diagram Sistem Informasi Pengelolaan luran Kematian

b. Activity Diagram

Activity diagram adalah memodelkan alur kerja (workflow) sebuah proses bisnis dan urutan aktivitas dalam suatu proses(Sasmito, 2017).

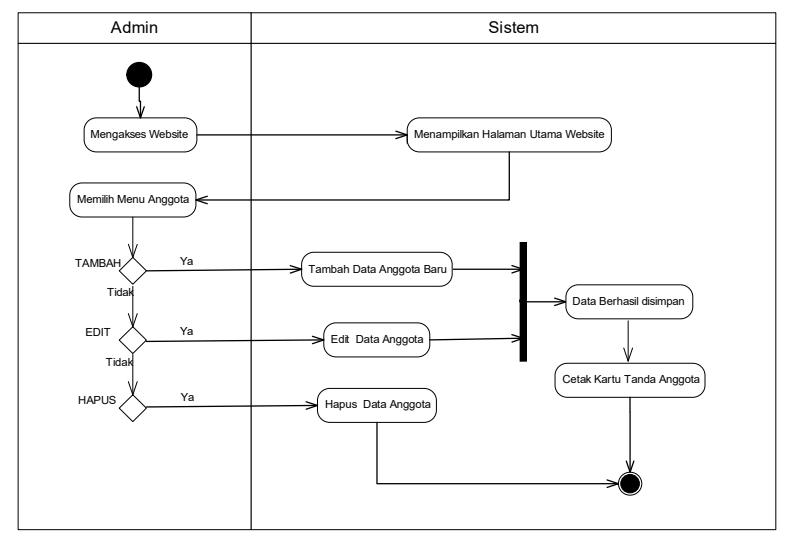

Gambar 3. Activity Diagram Kelola Data Anggota 


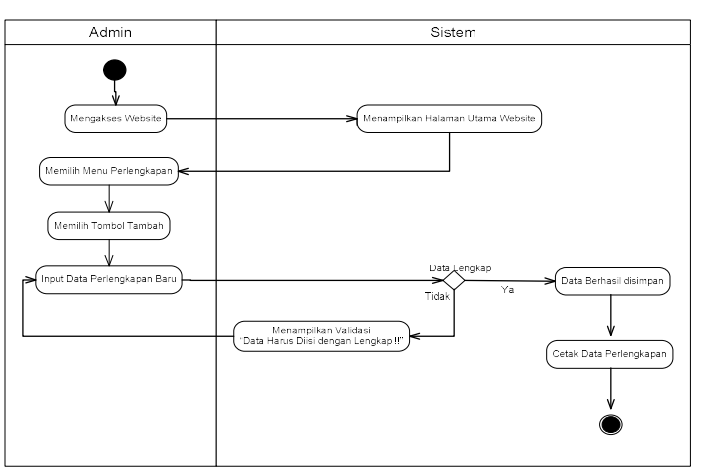

Gambar 4. Activity Diagram Kelola Data Perlengkapan

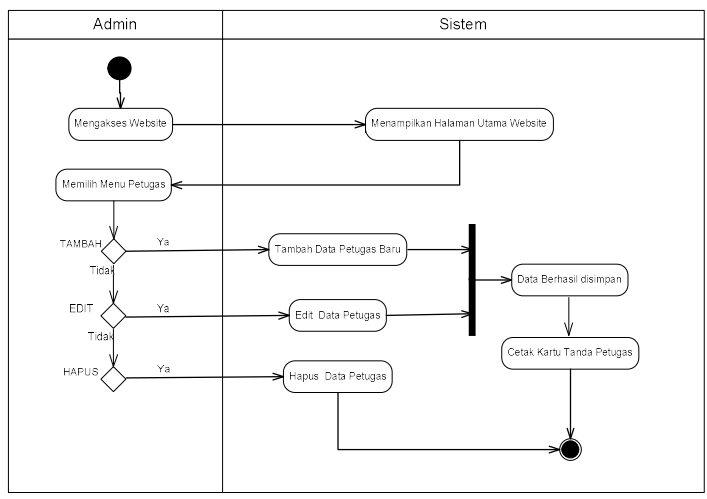

Gambar 5. Activity Diagram Kelola Data Petugas

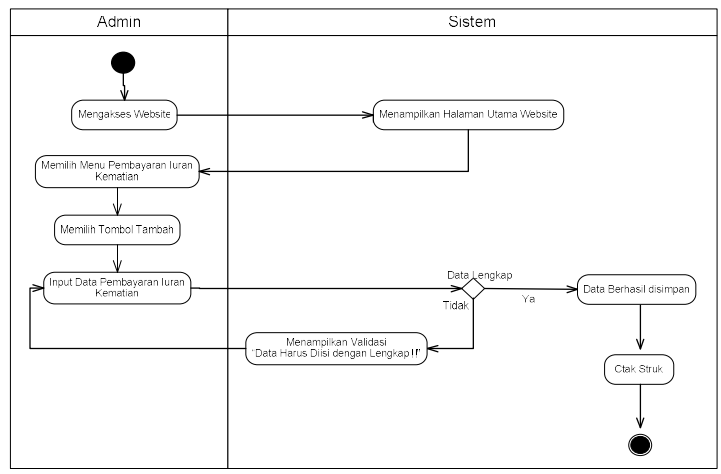

Gambar 6. Activity Diagram Tambah Data Pembayaran luran Kematian

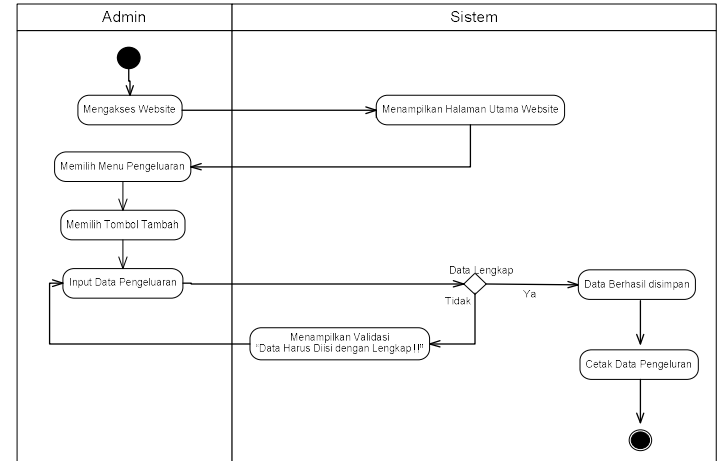

Gambar 7. Activity Diagram Tambah Data Pembayaran luran Kematian

c. Sequence Diagram

Sequence Diagram merupakan diagram menguraikan interaksi pemakai dengan sistem informasi menjadi deretan kegiatan pemakai dan tampilan sistem informasi(Nurdam, 2014).

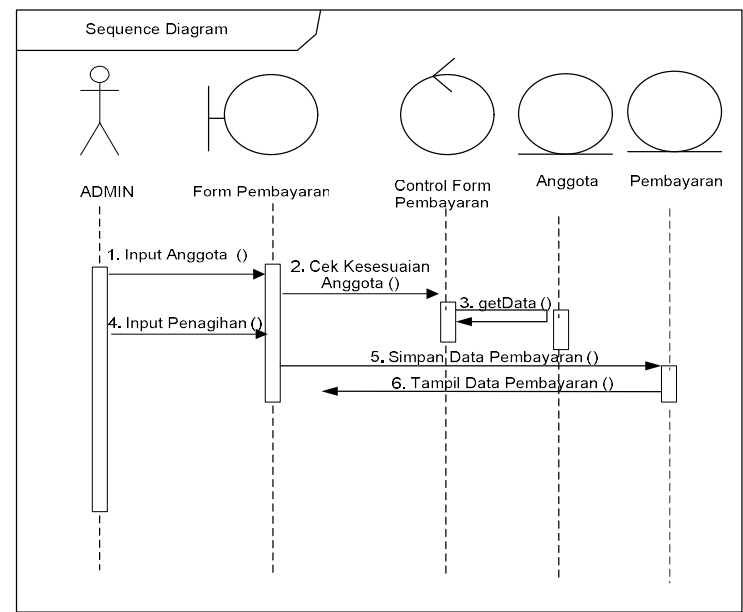

Gambar 8. Sequence Diagram Input Transaksi Pembayaran Iuran Kematian

2. Desain Database

a. Entity Relationship Diagram (ERD)

ERD (Entity Relationship Diagram) adalah model teknik pendekatan yang menyatakan atau menggambarkan hubungan suatu model. ERD menunjukan objek data (Entity) dan hubungan (Relationship), yang ada pada Entity berikutnya(Fridayanthie \& Mahdiati, 2016). Entity Relationship Diagram (ERD) yang menggambarkan hubungan / relasi antar

Entity pada sistem informasi pengelolaan iuran rukun kematian berbasis web sebagai berikut: 


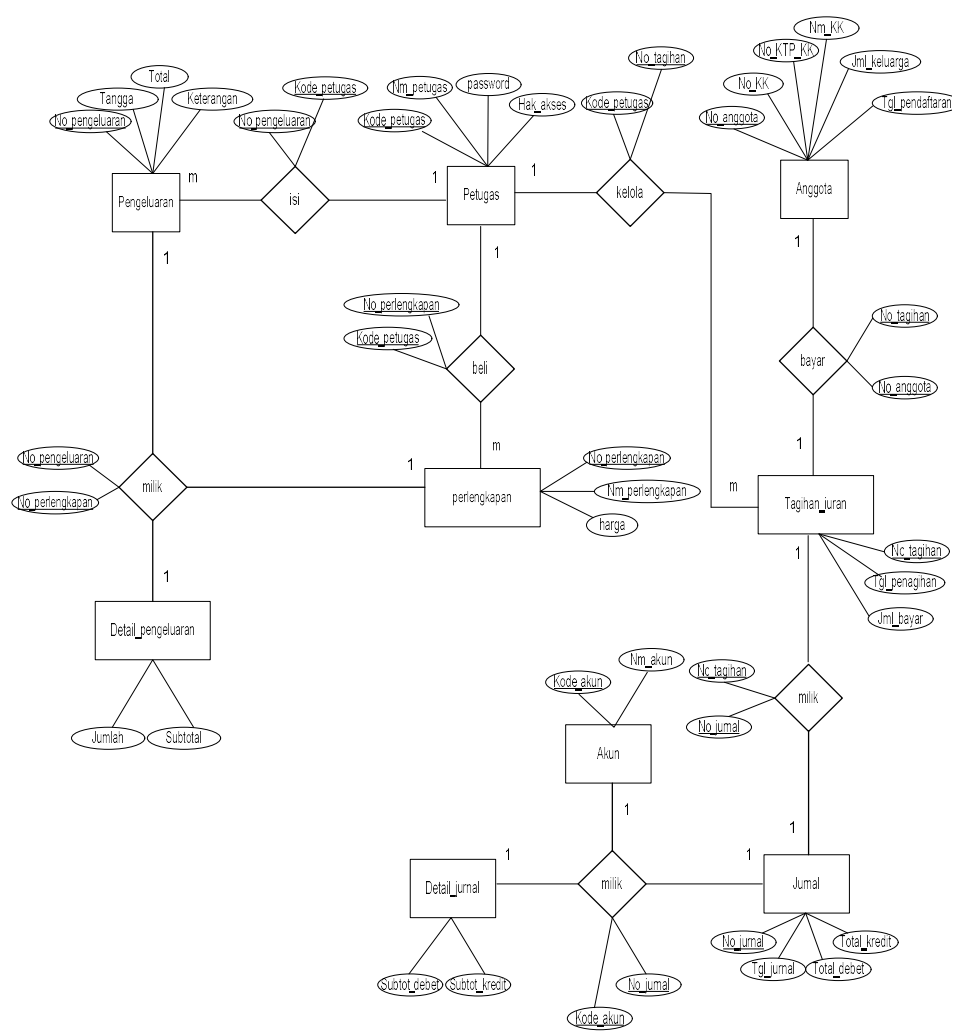

Gambar 9. Entity Relationship Diagram (ERD)

b. Logical Record Structure (LRS)

Logical Record Structure(LRS) adalah resperentasi dari struktur record-record pada tabeltabel yang terbentuk dari hasil relasi antar himpunan entitas atau biasa disebut dengan entity relationship diagram (Hidayat, 2017). LRS yang dibangun pada sistem informasi pengelolaan iuran rukun kematian berbasis web sebagai berikut:

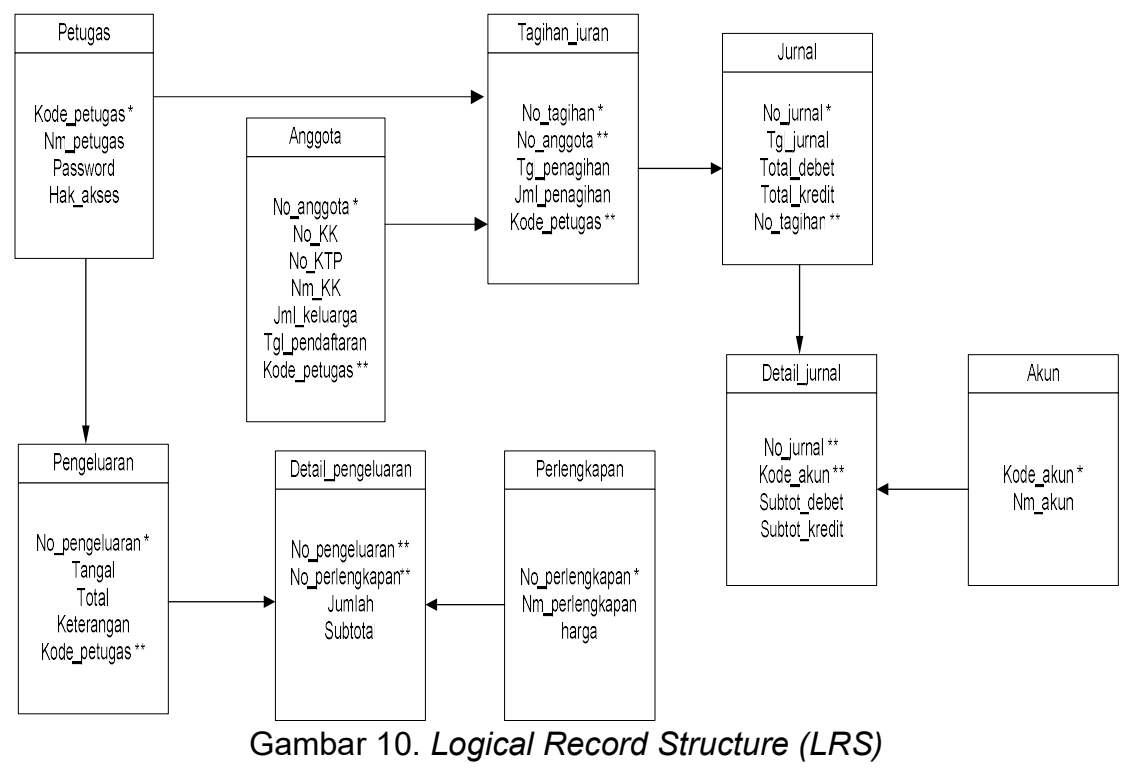




\section{c. User Interface}
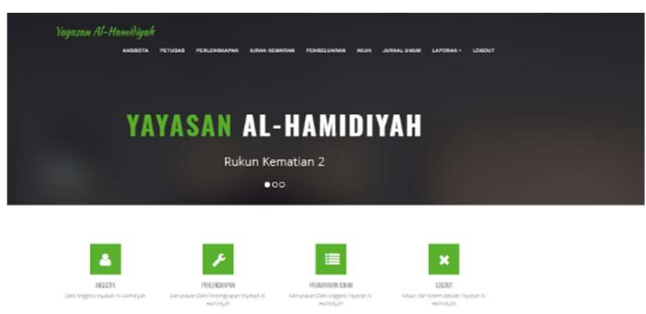

Gambar 11. Tampilan Halaman Utama

Halaman utama berisi menu-menu form seperti menu anggota, petugas, perlengkapan, iuran kematian, pengeluaran, akun, jurnal umum, dan logout.

\section{Yayaranen Al-Hemidityate}

LOGIN ADMIN

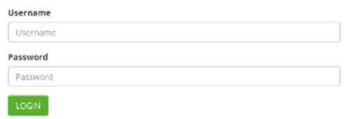

Gambar 12. Tampilan Halaman Login Admin

Halaman ini hanya bisa diisi oleh admin yang sudah memiliki username dan password.
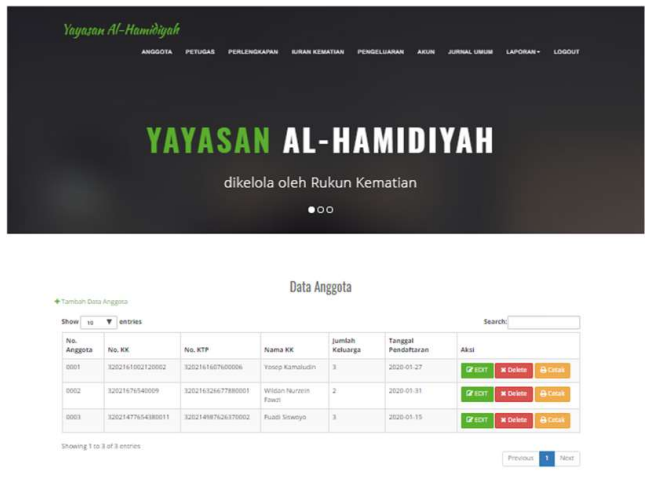

Gambar 13. Tampilan Halaman Data Anggota
Halaman data anggota digunakan untuk menambah data anggota baru, mengedit data anggota, menghapus data anggota dan mencetak data anggota.
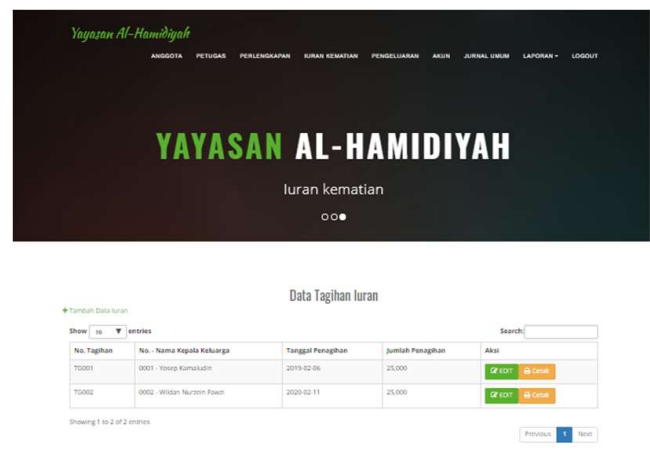

Gambar 14. Tampilan Halaman Data Iuran

Halaman data iuran digunakan untuk menambah data iuran, mengedit data iuran, cetak data iuran. Selain itu bisa melihat jumlah penagihan tiap anggota.
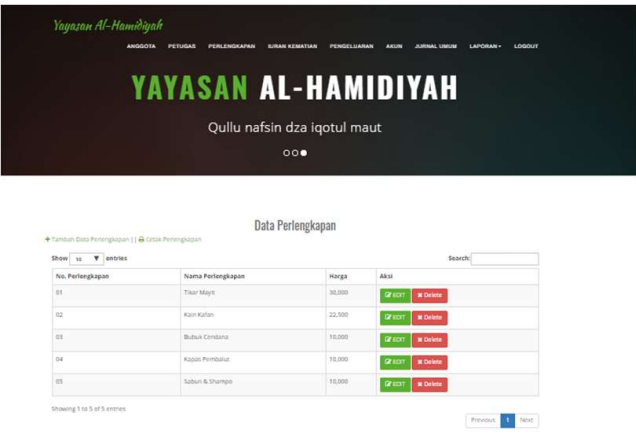

Gambar 15. Tampilan Halaman Data Perlengkapan

Halaman data perlengkapan digunakan untuk menambah data perlengkapan, mengedit data perlengkapan, dan menghapus data perlengkapan. 

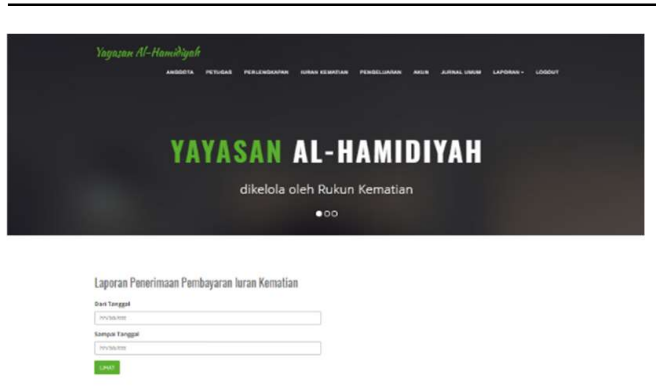

\section{Gambar 16. Tampilan Halaman Cetak Laporan}

3.4.

Pengujian

Pengujian sistem dilakukan dengan melakukan pengujian black-box terhadap semua fungsi dalam aplikasi. Dibawah ini
Halaman ini digunakan untk mencetak laporan pembayaran iuran kematian. Bisa dengan cara memfilter tanggal sesuai dengan kebutuhan.

\subsection{Pembuatan Kode program}

Pembuatan program dalam penelitian ini, rancangan hasil penelitian adalah membangun aplikasi dengan website. Maka dari itu penulisan program dilakukan menggunakan bahasa pemrograman PHP dengan basis data menggunakan MySQL

merupakan salah satu pengujian terhadap form login:

Tabel 1. Hasil Pengujian Black Box Testing Halaman Login Admin

\begin{tabular}{|c|c|c|c|c|c|}
\hline No & $\begin{array}{l}\text { Skenario } \\
\text { Pengujian }\end{array}$ & Test Case & $\begin{array}{l}\text { Hasil Yang } \\
\text { Diharapkan }\end{array}$ & $\begin{array}{c}\text { Hasil } \\
\text { Pengujian }\end{array}$ & Kesimpulan \\
\hline 1 & $\begin{array}{l}\text { Username dan } \\
\text { password tidak } \\
\text { diisi } \\
\text { kemudian klik } \\
\text { tombol login }\end{array}$ & $\begin{array}{l}\text { Username } \\
\text { (kosong) } \\
\text { Password: } \\
\text { (kosong) }\end{array}$ & $\begin{array}{l}\text { Sistem akan menolak } \\
\text { akses user dan } \\
\text { menampilkan validasi } \\
\text { "Harap isi bidang ini” }\end{array}$ & $\begin{array}{l}\text { Sesuai } \\
\text { Harapan }\end{array}$ & Valid \\
\hline 2 & $\begin{array}{lr}\text { Mengetikkan } & \\
\text { username } & \text { dan } \\
\text { password } & \\
\text { tidak } & \text { diisi } \\
\text { kemudian } & \text { klik } \\
\text { tombol login } & \\
\end{array}$ & $\begin{array}{l}\text { Username: } \\
\text { admin (benar) } \\
\text { Password } \\
\text { (kosong) }\end{array}$ & $\begin{array}{l}\text { Sistem akan menolak } \\
\text { akses user dan } \\
\text { menampilkan validasi } \\
\text { "Harap isi bidang ini." }\end{array}$ & $\begin{array}{l}\text { Sesuai } \\
\text { Harapan }\end{array}$ & Valid \\
\hline 3 & $\begin{array}{l}\text { Username tidak } \\
\text { diisi dan password } \\
\text { diisi kemudian klik } \\
\text { tombol login }\end{array}$ & $\begin{array}{l}\text { Username: } \\
\text { (kosong) } \\
\text { Password } \\
\text { admin (benar) }\end{array}$ & $\begin{array}{l}\text { Sistem akan menolak } \\
\text { akses user dan } \\
\text { menampilkan validasi } \\
\text { "Harap isi bidang ini." }\end{array}$ & $\begin{array}{l}\text { Sesuai } \\
\text { Harapan }\end{array}$ & Valid \\
\hline 4 & \begin{tabular}{l}
\multicolumn{3}{l}{ Mengetikkan } \\
salah satu kondisi \\
salah pada \\
username atau \\
password \\
kemudian klik \\
tombol login
\end{tabular} & $\begin{array}{l}\text { Username: } \\
\text { admin (benar) } \\
\text { Password: } 5 \operatorname{tr} 1 \\
\text { (salah) }\end{array}$ & $\begin{array}{l}\text { Sistem akan menolak } \\
\text { akses user dan } \\
\text { menampilkan validasi } \\
\text { "Usernamer Atau } \\
\text { Password } \\
\text { Salah" }\end{array}$ & $\begin{array}{l}\text { Sesuai } \\
\text { Harapan }\end{array}$ & Valid \\
\hline 5 & \begin{tabular}{lr}
\multicolumn{3}{l}{ Mengetikkan } \\
salah satu kondisi \\
salah \\
username pada \\
password \\
kemudian \\
$\begin{array}{l}\text { tombol login } \\
\text { klik }\end{array}$ \\
\end{tabular} & $\begin{array}{l}\text { Username: } \\
\text { AMD01 (salah) } \\
\text { Password: } \\
\text { admin (benar) }\end{array}$ & $\begin{array}{l}\text { Sistem akan menolak } \\
\text { akses user dan } \\
\text { menampilkan validasi } \\
\text { "Usernamer Atau } \\
\text { Password } \quad \text { Anda } \\
\text { Salah" }\end{array}$ & $\begin{array}{l}\text { Sesuai } \\
\text { Harapan }\end{array}$ & Valid \\
\hline 6 & $\begin{array}{l}\text { Mengetikkan } \\
\text { username dan } \\
\text { password } \\
\text { dengan data yang } \\
\text { benar kemudian } \\
\text { klik tombol login } \\
\end{array}$ & $\begin{array}{l}\text { Username: } \\
\text { admin (benar) } \\
\text { Password: } \\
\text { admin } \\
\text { (benar) }\end{array}$ & $\begin{array}{l}\text { Sistem menerima } \\
\text { akses login dan } \\
\text { kemudian langsung } \\
\text { menampilkan validasi } \\
\text { "Selamat Datang" }\end{array}$ & $\begin{array}{l}\text { Sesuai } \\
\text { Harapan }\end{array}$ & Valid \\
\hline
\end{tabular}




\subsection{Pendukung (support) atau pemeliharaan (maintenance)}

Untuk Pemeliharaan sistem informasi pengelolaan iuran rukun kematian dirancang dengan dilakukannya pemeriksaan secara periodik terhadap data pada aplikasi.

\section{Kesimpulan}

Dari hasil penelitian yang diperoleh, akurasi dari penggunaan algoritma klasifikasi K-Nearest Neighbor dalam prediksi Bank Marketing sebesar $74,37 \%$ dengan nilai $\mathrm{K}=9$, sedangkan untuk akurasi algoritma klasifikasi K-Nearest Neighbor dengan menggunakan feature selection sebesar $89,72 \%$ dengan nilai $\mathrm{K}=3$, sehingga didapat selisih peningkatan akurasi sebesar $15,35 \%$.

Berdasarkan penelitian yang telah dilakukan, maka dapat diambil kesimpulan sebagai berikut:

a. Sistem Informasi Pengelolaan Iuran Kematian berbasis Web ini dapat membantu setiap petugas yang terlibat langsung dalam proses pengelolaan iuran kematian untuk mengelola dan mendapatkan informasi dengan cepat, tepat dan akurat, sehingga dapat meningkatkan kualitas pelayanan dan efektivitas kerja dalam pengelolaan tersebut.

b. Dengan menggunakan Sistem Informasi Pengelolaan Iuran Kematian berbasis Web, proses pengelolaan iuran kematian antara pihak pengurus dan pihak tertagih menjadi lebih terorganisir dengan baik pada saat transaksi berlangsung, sehingga iuran menjadi merata dan lebih tertata.

c. Dengan adanya sistem ini, proses pembuatan dan percetakan laporan yang relevan menjadi lebih cepat dan mudah. Selain itu, keseluruhan data tersimpan dalam arsip digital (database) sehingga penyimpanan jauh lebih aman dan terhindar dari kemungkinan resiko kerusakan dan kehilangan.

\section{Referensi}

Fridayanthie, E. W., \& Mahdiati, T. (2016). RANCANG BANGUN SISTEM INFORMASI PERMINTAAN ATK BERBASIS INTRANET (STUDI KASUS: KEJAKSAAN NEGERI RANGKASBITUNG). JURNAL KHATULISTIWA INFORMATIKA, IV(2), 126-138.

Gumilang, G. S. (2016). METODE PENELITIAN KUALITATIF DALAM
BIDANG BIMBINGAN DAN KONSELING. Jurnal Fokus Konseling, 2(2), 144-159.

Hidayat, R. (2017). Aplikasi Penjualan Jam Tangan Secara Online Studi Kasus: Toko JAMBORESHOP. Jurnal Teknik Komputer, III(2), 90-96.

Hutari, T. (2018). Perancangan Dan Implementasi Sistem Informasi Iuran Rukun Kematian Berbasis Web Pada Rw 10 Kelurahan Jati Padang Timur Menggunakan Framework Codeigniter. Retrieved from http://repo.polinpdg.ac.id.

Jirhanuddin, Dakhoir, A., \& Sulistyaningsih. (2016). MANAJEMEN DANA IURAN RUKUN KEMATIAN DI PUNTUN KOTA PALANGKA RAYA. Jurnal Al-Qardh, 2(5), 127-140.

Muslimah, S. (2018). RANCANG BANGUN SISTEM INFORMASI PENGELOLAAN IURAN KEMATIAN BERBASIS WEB PADA YAYASAN AL-IKHLAS SUKABUMI. Retrieved from https://repository.bsi.ac.id/index.php/rep o/viewitem/18421

Nurdam, N. (2014). Sequence Diagram Sebagai Perkakas Perancangan Antarmuka Pemakai. ULTIMATICS, VI(1), 21-25.

Pressman, R. S. (2002). Rekayasa Perangkat Lunak: Pendekatan. Yogyakarta: Andi Publisher.

Rosa, A., \& Shalahuddin, M. (2015). Rekayasa Perangkat Lunak. Bandung: Informatika.

Sari, A. O., \& Nuari, E. (2017). RANCANG BANGUN SISTEM INFORMASI PERSEDIAAN BARANG BERBASIS WEB DENGAN METODE FAST ( FRAMEWORK FOR THE APPLICATIONS ). Jurnala Pilar Nusa Mandiri, 13(2), 261-266.

Sasmito, G. W. (2017). Penerapan Metode Waterfall Pada Desain Sistem Informasi Geografis Industri Kabupaten Tegal. Jurnal Informatika:Jurnal Pengembangan IT (JPIT), 2(1), 6-12. Retrieved from https://ejournal.poltektegal.ac.id/index.p hp/informatika/article/view/435

Widodo, P. P., \& Herlawati. (2011). Menggunakan UML. Bandung: Informatika. 